\title{
Marsilio de Padua o los orígenes del liberalismo político occidental
}

\author{
MAURICIO CHAPSAL ESCUDERO \\ Universidad de Santiago de Chile (Chile) \\ mauricio.chapsal@usach.cl
}

\begin{abstract}
Resumen
Este trabajo tiene por objeto investigar desde un punto vista histórico filosófico las consecuencias políticas de la separación entre la razón y la fe en el pensamiento de Marsilio de Padua (ca. 1275/80-1342/43). En él se explora la crisis que produce la aceptación irrestricta de la metafísica de Aristóteles, autor a partir del cual Marsilio realiza su análisis de la civitas, y algunas de sus consecuencias inmediatas en la filosofía política y el orden jurídico social de su tiempo: el uso de la razón pura como instrumento exclusivo de análisis social, la separación de la ley humana de la ley eterna, y la búsqueda y consecución del bien común inmanente por sobre el trascendente, antecedentes que conforman el inicio del llamado liberalismo político. A modo de conclusión, se intentará demostrar que algunos de los postulados básicos que caracterizan el pensamiento liberal político moderno se encuentran virtualmente precontenidos en el pensamiento de este filósofo medieval.

Palabras clave: Liberalismo Político, Razón-Fe, Edad Media, Orden Político, Bien Común, Causalidad Política.
\end{abstract}

\section{Marsilius of Padua or the origins of western political liberalism}

\begin{abstract}
This work aims to investigate from a historic and philosophical point of view, the political consequences of the break up between faith and reason in Marsilius of Padua's thought (ca. 1275/801342/43). It's explored the crisis generated by the unrestricted acceptance of Aristotle's metaphysics, from whom Marsilius raises his analysis of the civitas, and some of the immediate consequences in the political philosophy and the legal social order of his time: the use of pure reason as an exclusive instrument of social analysis, the separation of the human law from the eternal law, and the research and attainment of the immanent common good over the transcendent one, a background that builds the so called political liberalism. As a way to conclude, we'll try to demonstrate that some of the basic premises that distinguish the modern liberal thought are virtually pre-held in Marsilius of Padua's philosophy.

Key words: Political Liberalism, Reason-Faith, Middle Ages, Political Order, Common Good, Political Causality.
\end{abstract}

Doctor en Filosofía por la Pontificia Universidad Católica de Valparaíso. Profesor de Filosofía Política, Filosofía Medieval y Metafísica del Departamento de Filosofía de la USACH.

Agradecimientos al Proyecto de Investigación DICYT 031453CHE, Vicerrectoría de Investigación, Desarrollo e Innovación, Universidad de Santiago de Chile.

Recibido: 7/Abri1/2016 - Aceptado: 3/Junio/2016 


\section{Introducción}

Es sabido que el pensamiento racional que dominó la cultura antes del siglo XIII se caracterizó en general por su férrea unidad con la fe cristiana. Este siglo, ciertamente, señala históricamente el punto culminante de una Europa que se llamaba a sí misma Cristiandad, unidad religiosa, política y social bajo la autoridad del emperador y del Papa, cohesionada por una fe común, y el advenimiento de una serie de novedosas ideas que a la postre terminarán por conformar lo que más adelante se llamará Edad Moderna ${ }^{1}$. En efecto, profundizando el sentido de esta última afirmación y a modo de caracterización de la época a la cual nos referimos, es posible afirmar que los diversos estamentos de la sociedad medieval previos a dicho siglo se estructuraban sobre la base de tres principios esenciales, a saber:

a.- Dios existe y gobierna el mundo mediante la ley divina.

b.- Dicha ley ha sido infusa por Dios en la conciencia de cada persona en forma de ley natural, hecho que nos permite distinguir espontáneamente el bien del mal; al mismo tiempo, ha sido también revelada en el Antiguo y Nuevo Testamento, y plasmada esencialmente en el Decálogo.

c.- Existe una vida después de ésta que queda condicionada por lo que en este mundo se haya hecho o dejado de hacer; existe, por lo tanto, la posibilidad de un castigo eterno, como existe también la de una recompensa eterna.

Las implicancias de estos tres principios en el orden práctico social resultaban -en mi opinión- fundamentales por tres razones:

a.- En la medida en que existe una ley natural como reflejo de la ley divina (ley eterna), toda ley positiva (humana) debía tomar como referente esa ley natural y no entrar en contradicción con ella ${ }^{2}$. De este modo, la

1 Para una mejor comprensión de este problema véase Claves para comprender la separación razón-fe en el siglo XIII y sus implicancias filosóficas posteriores (Chapsal, 2013: 47).

2 El ejemplo más típico de esta actitud se encuentra en Juan de Salisbury (ca. 1.1151.180) para quien el Príncipe siempre debe tener en mente la ley de Dios para tener un correcto actuar, pero para ello requiere de un constante perfeccionamiento "académico" para su correcta interpretación y comprensión. Ello implica un seguimiento constante de los dictados del Deuteronomio, tal como príncipes cristianos de la talla de Teodosio, Constantino y Justiniano lo hicieron. En efecto, a su juicio toda ley debe estar en conformidad con la disciplina eclesiástica, por lo que el príncipe debe ser versado en ésta, cuestión que está en conformidad, además, con lo expresado en el 
ley natural se constituía en el marco que proporcionaba cohesión y legitimidad a la ley positiva, la cual, además, en virtud precisamente de su coherencia con esa fe común y de su último fundamento en la ley divina, era más fácilmente comprendida, asumida y respetada. La idea, por consiguiente, de una ley positiva construida sólo por el hombre independiente de la ley divina no tiene sentido en la sociedad medieval de esa época.

b.- El fundamento de la ley positiva en la ley natural reforzaba la universalidad de la primera, esto es, la convicción y común aceptación de que nadie estaba exento de cumplir la ley, desde el rey hasta el último súbdito. En todos los niveles de la sociedad era igualmente exigible ese cumplimiento, tanto más cuanto ningún hombre o autoridad terrena podía estar por sobre la ley divina.

c.- Existía una clara conciencia del mal (transgresión a la ley) tanto en aquel que lo realizaba como en la sociedad; el indiferentismo moral como legal no se da en la sociedad medieval. Lo anterior redundaba además en la aplicación y aceptación del castigo por faltas cometidas. Ciertamente, esto no significa que no hubiesen delitos en esta época de la historia; no obstante, se actuaba con el convencimiento de que la transgresión no podía quedar impune, y si el transgresor no recibía el castigo en esta vida, terminaría recibiéndolo en la otra por cuanto existe un "poder sobrehumano", del que la Iglesia da razón, que termina siempre aplicando la justicia. En este sentido, el temor a la posibilidad de un castigo eterno actuaba en gran medida como freno de la transgresión, o bien, una vez cometida ésta, como incentivo para su reparación, y ello en todos los niveles de la sociedad. Son conocidos los casos de reyes que, habiendo cometido algún crimen, solicitaban el perdón del Papa y asumían durísimas penitencias para expiar su culpa. Por otra parte, la posibilidad de excomunión actuaba también como freno poderoso a los excesos de la libertad y del poder humano.

Esos eran, en términos generales, los principios fundantes del orden social de los siglos XII y XIII, siglos que coinciden con la culminación del esplendor del arte, la arquitectura y el pensamiento en Europa. Es la época de comienzo del arte gótico, de las Sumas y las Disputas de Tomás de Aquino, por ejemplo. Lamentablemente, en los siglos posteriores, esta unidad de fe y razón reflejada en la cultura y sociedad de la época se

capítulo 4 del Deuteronomio donde se establecen con claridad las características morales del gobernante; de allí que ocasionalmente debe dejarse aconsejar por letrados que posean conocimiento acabado de la disciplina anteriormente nombrada (de Salisbury, 1984: 320).

VERITAS, No 35 (Septiembre 2016) 
romperá ${ }^{3}$ con el pensamiento de Marsilio de Padua, tesis que a continuación intentaremos demostrar, comenzando así un largo y sutil periodo de deterioro de los tres principios antes enunciados que alcanza a nuestros días constituyendo, de este modo, lo que, en último término, bien podríamos llamar liberalismo político occidental.

\section{Origen de la emancipación}

El 24 de Junio de 1324 Marsilio de Padua termina de escribir el Defensor de la Paz, obra concebida como respuesta a la crisis de poder entre la Iglesia y el Estado acaecida en su tiempo. En ella se puede advertir sin mayores inconvenientes un marcado giro en la relación con la Iglesia. En este autor el ataque a Roma es explícito. Por el contrario, la exaltación de Aristóteles como figura representativa y máxima autoridad de lo que debe ser la filosofía y la sociedad resulta evidente. El denominador común en todo su pensamiento es la emancipación, en particular, de la sociedad, del saber, especialmente la filosofía práctica, de toda tutela eclesiástica. A su juicio es preciso terminar cuanto antes con esta "enfermedad" (peste), con esta "singular malignidad", expresiones que se encuentran explícita y reiteradamente a lo largo de la Tercera Parte de la citada obra medieval. Para ello el pensamiento de Aristóteles resulta fundamental. No obstante, conviene destacar desde un comienzo que el uso que hace Marsilio del filósofo griego no es exacto advirtiéndose desde el principio una gran cantidad de citas del Estagirita efectuadas por este autor medieval con el propósito manifiesto de exaltar la autonomía de la razón y la voluntad por sobre la fe cristiana, alejándose así de la inspiración original de La Política aristotélica, obra en donde no resulta difícil encontrar más de alguna proyección teológica. Con todo, Aristóteles es llamado con frecuencia "el eximio entre los filósofos". En este contexto, por tanto, se comprende que la noción que abre el Defensor de la Paz sea la de suficiencia. En efecto, Marsilio comienza destacando que la ciudad y la filosofía, en cuanto perfectas, reúnen en sí todos los requisitos de acabada completitud e independencia. Dicha tesis, en la pluma del Paduano, equivale a decir que la ciudad y el saber liberal no requieren de ninguna supervisión externa o superior a ella:

3 En relación a este punto, y en particular a lo ocurrido a la Iglesia con posterioridad al siglo XIII, E. Gilson afirmó: “...privada de toda autoridad para intervenir en lo temporal, la Iglesia se encuentra relegada a la esfera de lo sobrenatural y a todo lo que prepara la vida eterna. En cuanto a la Ciudad, se prepara a sí misma según el arte de sus artesanos y los consejos de los filósofos. La ruptura de la Cristiandad es un hecho consumado" (Gilson, 1972: 641). 
Es, pues, la ciudad, según Aristóteles, $1^{\circ}$ de la Política, cap. $1^{\circ}$ : una comunidad perfecta, que llena por sí todos los requisitos de suficiencia, como es consecuente decir, creada ciertamente para vivir y persistiendo para bien vivir. Y lo que dice Aristóteles: creada para vivir y persistiendo para bien vivir, significa la causa final perfecta de la misma, porque los que viven civilmente no sólo viven, lo que hacen las bestias y los esclavos, sino viven bien, se dedican, en efecto, a las actividades liberales, como son las de las facultades del alma, tanto de la práctica como de la especulativa (de Padua, 2009: 14).

Tal como lo muestra la cita, la vida buena demanda todo lo necesario para la subsistencia humana, en particular y como rasgo perfectivo de ella, las actividades del alma tanto prácticas como especulativas (filosofía). Se trata, como se puede observar, de una suficiencia que supone en última instancia la autonomía o libertad que no se encuentra en las bestias y los esclavos. En otras palabras, el buen vivir perfecto, causa final de la vida humana, exige implícitamente desde un comienzo la autodeterminación social y epistémica, única manera de garantizar el bienestar de la ciudad (paz) y la auténtica felicidad humana. Esta misma teleología permitirá a nuestro autor explicar, además, la aparición de la ciudad. En efecto, la diferencia en el grado de consecución entre el bien vivir, causa final de la comunidad política perfecta, y bienes particulares o imperfectos en relación a aquel, le permite explicar la historia social del hombre. Siguiendo en este punto una vez más a Aristóteles, el Paduano explicará la aparición de la ciudad como resultado de un desarrollo histórico creciente (progreso) de comunidades menos perfectas hacia las más perfectas (de Padua, 2009: 12). Así, a partir de las primeras comunidades se generó la casa, y luego la aldea. A ello agregará que el paso desde esa comunidad primitiva a la ciudad se explica mediante el incremento de la experiencia del hombre y el desarrollo de la razón, de lo que a su vez resulta una clara distinción y complejización entre las partes de la ciudad en relación con las comunidades anteriores (evolucionismo político). Esas partes se corresponden con la aparición de las artes necesarias para el bien vivir. Es en este contexto donde nuestro autor introduce el principio de vida suficiente. Inicialmente los hombres se encuentran en el mismo plano que los animales, pero se diferencian de estos en el modo como tienden a satisfacer la situación de falencia o indigencia natural de su especie. Por tanto, el impulso hacia la ciudad encuentra su origen en la precariedad de la naturaleza humana, es decir, en la condición natural de indigencia material del hombre, siempre inferior en comparación con los animales, pero superior en virtud de su alma racional gracias a la cual se generan distintas artes para superar las eventuales adversidades de su 
situación. Y como tales artes sólo pueden ser ejercitadas a través del concurso de muchos hombres, fue preciso que los hombres se reunieran para obtener los beneficios que derivan de ellos, y evitar así los mencionados perjuicios:

Hubo, pues, hombres asociados para tener una suficiencia de vida, con poder para procurarse las cosas necesarias antes reseñadas, comunicándoselas entre sí. Esta agrupación así perfecta y con una extensión suficiente se llamó ciudad, cuya causa final y plural diversidad de partes ya se ha declarado de algún modo y en lo siguiente se declarará más por menudo. Porque siendo necesarias a los que quieren vivir suficientemente diversas cosas que no pueden procurarse por hombres de un solo orden u oficio, convino que hubiese diversos órdenes y oficios de hombres en esa comunidad, ejercitando y procurando esas tales cosas, de las que los hombres necesitan para su vida suficiente, y estos diversos órdenes u oficios no son otra cosa que la pluralidad y división de las partes componentes de la ciudad (de Padua, 2009: 17).

En síntesis, como se puede observar, el origen de la ciudad y su organización política se encuentra, por una parte, en la precariedad de la naturaleza humana $y$, por otra, en la necesidad de autocompletar la misma, hecho que se realiza distribuyendo las tareas sociales en diversos grupos u oficios, es decir, ordenando la ciudad. En este contexto, por consiguiente, de conformación, desarrollo, y autocompletitud del bien vivir, a su juicio la causa eficiente motora que establece, distingue, y separa inicialmente las partes de la ciudad no puede ser sino el legislador humano (de Padua, 2009: 54) que, en última instancia, no es otro que el mismo pueblo, principio motor o alma de la ciudad. Así lo declara Marsilio: "digamos, pues, mirando a la verdad y al consejo de Aristóteles en el $3^{\circ}$ de La Política, cap. 6, que el legislador o causa eficiente primera propia de la ley es el pueblo, o sea, la totalidad de los ciudadanos, o la parte prevalente de él por su elección y voluntad expresada de palabra en la asamblea general de los ciudadanos" (de Padua, 2009: 54). Obsérvese una vez más que la verdad y la opinión de Aristóteles se corresponden. Partiendo de esta consideración se comprende, por tanto, que el Paduano conciba al pueblo además como causa material, esto es, como un ente concreto o persona ficticia (corporatio) cuya parte más importante es la denominada "maior et melior pars". La maior et melior pars, también denominada valentior pars, viene a significar aquí aquella parte esencialmente comprometida con la preservación y desarrollo de la ciudad (prevalente), o sea, como bien afirma O. Godoy (2003), la parte del pueblo compuesta por ciudadanos animados por el amor al servicio público, esto es, a la grandeza y subsistencia del reino (Bien Común). Esta parte también recibe la apela- 
ción de principans pars por ser ella el núcleo esencial desde el cual despliega sus efectos la causalidad eficiente que anima la existencia, unidad y continuidad de la ciudad. Por tanto, cualquiera sea la forma y número que adopte, el gobierno, en cuanto causa eficiente, es la parte de la ciudad que tiene poder para mandar, juzgar, y ejecutar sobre los oficios y actos civiles según la ley (causa formal) ${ }^{4}$, es decir, que puede dictar sentencia y castigar los delitos. En su origen, la función legislativa compete al pueblo o conjunto de ciudadanos, que es también el titular del poder coactivo, y si el gobernante está legitimado para el uso de la fuerza coactiva de la ley, es por voluntad del legislador, es decir, del pueblo (de Padua, 2009: 73). De este modo, es el alma del conjunto de ciudadanos quien comunica a esta parte primera o principado, además de la autoridad para mandar, juzgar, premiar, castigar, y ejecutar, el poder de instituir las demás partes de la ciudad; y lo hace no por derecho propio, sino por atribución del legislador (pueblo), de modo que al ejercer el poder actúa como causa eficiente ejecutora del conjunto de ciudadanos (de Padua, 2009: 75) . $^{5}$ para no poner en peligro la vida social y la paz que ha de defender, la función del príncipe no puede detenerse nunca, su jurisdicción no debe entorpecerse, como no puede cesar la actividad del corazón que garantiza la salud y la vida de un cuerpo sano natural (de Padua, 2009: 76).

\section{Hacia una disolución de la Iglesia}

Así pues, la ciudad se compone de diferentes partes que son, en realidad, los oficios que procuran las cosas necesarias para la vida humana suficiente. De este modo hay agricultores, artesanos, tesoreros, soldados, jueces o consejeros, $\mathrm{y}$, en principio, sacerdotes, porque la comunidad requiere esos oficios para su autárquico bien vivir. A su entender las cinco primeras partes u oficios se justifican por su necesidad para realizar la vida buena (felicidad) en este mundo (material), causa final de la ciudad y de su pluralidad de partes. Pero la parte sacerdotal, en este contex-

4 "Las causas formales de los oficios, en cuanto han sido instituidos y son partes de la ciudad, son las normas directivas de la causa eficiente, transmitida o impresa en aquellos que en la ciudad están designados para llevar a cabo determinadas obras" (de Padua, 2009: 31).

5 Además: "Las causas motoras o ejecutoras de los oficios, en cuanto significan hábitos del alma, son las voluntades de los hombres, sus conocimientos y deseos, o cada uno de por sí, o todos juntos indistintamente. De algunos es también principio el movimiento y el ejercicio de los órganos corporales. Pero su causa eficiente, en cuanto son partes de la ciudad, es el legislador humano frecuentemente y las más de las veces, si bien en otro tiempo y rara vez y en poquísimas cosas de alguno o de algunos fue Dios la causa motora inmediata, sin humana determinación alguna (...). Sobre el sacerdocio hay otra forma de institución" (de Padua, 2009: 31-32).

VERITAS, No 35 (Septiembre 2016) 
to, no resulta a nuestro autor necesaria para la suficiencia de vida, pues no corresponde con ninguna necesidad material vital. Con ello, y adelantándose a su tiempo, Marsilio se propone situar correctamente el origen y las funciones del sacerdocio, esto es, como una parte de la comunidad y no como un poder por encima de ella. La causa final (para qué) de esta "parte de la ciudad cristiana" se funda en la revelación divina: como el pecado corrompió la inocencia original, Dios envió al mundo a su Hijo, a través del cual instituyó el sacerdocio cristiano encargado de administrar los sacramentos y proporcionar ayuda a las almas para conseguir la felicidad humana en el otro mundo. Así, la causa final por la que fue instituido en la comunidad de los fieles el verdadero sacerdocio es "...la moderación de los actos humanos imperados por el conocimiento y el apetito, tanto de los inmanentes como de los transeúntes, según que por ellos el género humano se orienta al óptimo modo de vivir que es el del mundo futuro" (de Padua, 2009: 25).

Por tanto, como bien afirma Óscar Godoy:

La Iglesia, según Marsilio, sólo detenta un poder que el mismo denomina 'de llaves', las que permiten el acceso de los hombres a la salvación y la gloria eterna. Básicamente esas 'llaves', que abren las puertas de la salvación, son el poder de absolver los pecados y de administrar el sacramento de la eucaristía... El Papa no puede substituir a la fuente natural del poder civil, que es el pueblo. Marsilio se refugia en el principio general que afirma que solamente hay gobierno legítimo allí donde la comunidad lo ha establecido por consenso (Godoy, 2003: 350 y 352).

En suma, la Iglesia carece de poder temporal. Más aún, como cualquier otra parte de la sociedad está sometida a la ley, es decir, a la causa formal de la ciudad la que, como tal, se identifica con el legislador quien a su vez, en última instancia, no es otro -como decíamos- que el mismo pueblo (de Padua, 2009: 74). De este modo, la paz -al igual que cualquier virtud aristotélica- se fundamenta en el orden de la comunidad, esto es, en la justa disposición y función de los individuos (oficios), hecho que garantiza la armonía y tranquilidad social (justicia). En este contexto, por tanto, resulta claro que la parte sacerdotal no puede salirse de su función y ejercer acciones que no le corresponden. En efecto, en cuanto a la relación entre Estado e Iglesia, sostiene Marsilio que ambos se componen de las mismas personas, aunque agrupadas de modo diferente. En el mundo venidero, el poder espiritual tendrá la preeminencia. En este mundo, el poder profano es el supremo. En este sentido la supremacía del Estado, esto es, la autonomía del poder político civil, resulta clara para el $\mathrm{Pa}$ duano. La fundamentación de dicha autonomía una vez más descansa en 
Aristóteles: la Ciudad es creada para vivir, existe para vivir bien en el sentido secular del término. Por tanto, el bien extramundano, la vida eterna, etc., no cuentan como principio constitutivo de la misma. El principio primero o fin último de la ciudad desde su origen -tal como lo hemos afirmado anteriormente- es procurar las necesidades materiales e intercambiar mutuamente los bienes capaces de satisfacerlas. ¿Qué le queda entonces al sacerdocio al tiempo que lo excluye del bien vivir temporal de la ciudad? A su entender a este oficio le corresponden sólo los asuntos propios de la salvación del alma aunque con limitaciones. Teniendo presente este punto, Marsilio introduce en el sacerdocio una distinción entre, por una parte, el estado sacerdotal, de origen sobrenatural, instituido por Cristo en el alma de cada sacerdote con fines sólo espirituales y carente de carácter coactivo (de Padua, 2009: 28) y, por otra, una de origen humano, instituida para la mejor organización interna de la Iglesia. Es en este orden de cosas que el Paduano excluye de la ciudad al estado sacerdotal y lo somete al poder de la parte gobernante de la civitas, de la cual proviene toda preeminencia de un hombre sobre otros (de Padua, 2009: 536). Con ello mantiene el sacerdocio en la ciudad, pero sin otorgarle máxima jurisdicción, esto es, sin que la racionalidad de la civitas entre en contradicción con el carácter revelado del sacerdocio y, lo que es aún más importante, colocando una parte del sacerdocio cristiano dentro del espectro del bien vivir, que cae bajo la jurisdicción del gobernante temporal. Pero, por otro lado, la propia organización de la Iglesia (jerarquía) aparece en nuestro autor, consciente o inconsciente de ello, como un producto histórico de la creación humana y no como una institución divina. En consecuencia, por ser la Iglesia fruto de una asociación voluntaria que se preocupa de lo sobrenatural, no tiene sentido plantear en el seno de ella cuestiones de poder, que sólo son propias de los reinos seculares. Esta última afirmación Marsilio (de Padua, 2009: 338) la sustenta en el hecho de que Cristo nunca confió a la Iglesia ningún poder o dominio. Así disuelve la Iglesia como institución, ya que todo lo institucional que se encuentra en ella queda absorbido por la organización secular o estatal. La finalidad de la Iglesia es, pues, puramente sacerdotal y por ello debe estar alejada del poder. Su función es dedicarse a la enseñanza de lo que hay que creer y hacer para conseguir la salvación según el Evangelio: "El fin, pues, sacerdotal es la enseñanza y la información de lo que, según la ley evangélica, es necesario creer, hacer y omitir para conseguir la eterna salvación y huir de la perdición” (de Padua, 2009: 28). 


\section{Hacia una concepción laicista del Estado}

En suma, lo anterior no sólo conduce a nuestro autor a separar el poder civil del religioso, sino además a someter lo religioso al poder civil, es decir, al Estado. Del momento en que la sociedad es algo que ha surgido naturalmente, el Estado ha sido creado por la utilidad que tiene por y para sus miembros. Por tanto, la soberanía reside en el pueblo por medio del control popular y con las limitaciones de la ley, que también procede del pueblo, causa eficiente primera del gobierno y de la conformación del Estado. En este contexto, es claro que el hombre se juega su felicidad en el bien vivir, esto es, en la satisfacción de bienes inmanentes y no trascendentes (extramundanos). Paralelamente la filosofía, máxima aspiración del saber humano, se circunscribe al ámbito de lo natural. Es este saber -como hemos visto- el que precisamente viene a determinar, a la luz de Aristóteles, la naturaleza de los distintos oficios que contribuyen a la obtención de los bienes materiales necesarios partiendo de la consideración de la propia naturaleza humana y el que le permite, además, comprender al hombre como causa material de la ciudad a la luz de sus respectivos oficios.

"Diremos que la materia propia de los diversos oficios, en la medida en que los oficios se denominan hábitos del alma, son los hombres, inclinados por su misma generación o nacimiento a diversas artes o disciplinas. Porque, no faltando la naturaleza en las cosas necesarias, y siendo más cuidadosa en las más nobles, como entre los seres corruptibles es la especie humana, de la cual, perfeccionada por las diversas artes y disciplinas, es conveniente que, como de materia, se constituya la ciudad y sus partes en ella necesarias para obtener la suficiencia de vida (...). A algunos, así pues, engendró aptos para la prudencia, porque de prudentes debe componerse en la ciudad la parte judicial y deliberativa; a otros los engendró aptos para el vigor y la audacia, pues de los tales convenientemente se constituye la parte militar (...). Y así aparecen ya bastante claras las causas materiales de los oficios de la ciudad, según que suelen llamar oficios a las partes de la ciudad. Estas son los hombres experimentados en las artes y disciplinas de diversos géneros y especies, de los que se forman los diferentes órdenes o partes en la ciudad, con miras a las suficiencias finales provenientes de las artes y disciplinas de ellos; por donde con propiedad se dicen partes de la ciudad los oficios, como si dijéramos servicios, pues mirados como están establecidos en la ciudad, se ordenan al servicio y regalo de los hombres" (de Padua, 2009: 30).

El hombre, pues, no tiende naturalmente sólo a la comunidad política, como afirmaba Aristóteles, sino que en última instancia tiende natu- 
ralmente hacia la autosuficiencia de la vida, esto es, a la satisfacción plena de sus necesidades, hecho que conduce colectivamente al bien común por medio de su propia autonomía y libertad. De este modo, por tanto, la comunidad política resulta ser la respuesta organizada y específicamente humana (racional) a la necesidad de satisfacer esa tendencia natural hacia la superación de inicial indigencia. A la luz de esto último se comprende, por tanto, la intención del filósofo de Padua por independizar la teoría política de cualquier instancia que no sea sí misma y para ello el camino más rápido es destacar la autonomía del poder temporal en orden a la organización de sus propios asuntos. En esta independencia del Estado respecto del poder espiritual radica su principal tesis basada como hemos visto- en una interpretación naturalista de la política, esto es, en la creencia en la capacidad de los ciudadanos, en virtud de su pura razón, para ordenar sus propios asuntos en la esfera del Estado sin recurrir a la divinidad o a sus representantes en este mundo. No hay, pues, para este autor ninguna institución superior al Estado como cuerpo de ciudadanos. Ciertamente, el cuerpo de ciudadanos contempla una parte gobernante cuyo modo de elección sigue la costumbre de cada Estado; pero la autoridad de éste (principado o lo que sea) deriva en cualquier caso del acto legislativo de todo el cuerpo de ciudadanos ${ }^{6}$, es decir, de su causa eficiente, de ahí que sea esencial que esa autoridad se ejerza con arreglo al derecho y que sus deberes y poderes sean los que determine el conjunto de ciudadanos. En este contexto, el deber de la parte ejecutiva es supervisar que cada una de las partes del Estado desempeñe su función adecuada para el buen vivir del conjunto (justicia); para ello dispone de la coerción, si no lo hace así, puede ser destituida por el mismo poder que la eligió, a saber, el pueblo. De este modo, por tanto, la preferencia de Marsilio por un gobierno electivo frente a otra forma de gobierno de su tiempo (monarquía hereditaria) resulta evidente (trad. 2009: 88). La anhelada paz civil, fin último de su obra El Defensor de la Paz, se logra si cada parte se limita a cumplir las tareas que le corresponden. Para evitar los conflictos hay que considerar a esta totalidad compleja (ciudad) como una unidad. De la unidad del cuerpo social concluye nuestro autor la unidad del mando: un solo gobierno (Marsilio de Padua, trad. 2009: 98). Este gobernante único debe gobernar según la ley, que tiene su causa eficiente en el pueblo, es decir, en la voluntad popular, en quien reside en

6 "Para poner más claro lo dicho por Aristóteles y para reducir a un capítulo los modos todos de instituir los otros sistemas de gobierno, diremos que todo gobierno, o es conforme a la voluntad de los súbditos, o es sin su voluntad. El primero es el género de los gobiernos bien temperados, el segundo el de los viciosos" (de Padua, 2009: 3738).

VERITAS, No 35 (Septiembre 2016) 
última instancia, según este interesante autor medieval, la única fuente de poder político legítimo.

\section{A modo de conclusión}

1) De lo dicho hasta aquí resulta claro que para este autor medieval el ente político queda estructurado en base a cuatro principios tomados de la metafísica de Aristóteles: la causa final (bien vivir), la causa eficiente (príncipe, asamblea o el legislador), la causa formal (estructura, configuración, o las leyes del Estado), y la causa material (ciudadanos). Si bien es cierto en Aristóteles se trata de co-principios que confluyen en la explicación de un ente cualquiera, no obstante, son en sí mismos diferentes. Por el contrario, en Marsilio dichos principios (causas) se superponen al punto de mezclarse y/o confundirse entre sí. El carácter necesario de los mismos resulta evidente pues la inexistencia de alguno de ellos implica la destrucción o inexistencia del Estado. Por tanto, de la forma como se correlacionan estos elementos, esto es, la importancia, primacía o, por el contrario, no consideración o pérdida de la vigencia de alguno de ellos, depende la salud del Estado, es decir, la paz (justicia) o subsistencia del mismo. En este contexto, la justicia se da en el orden o adecuada función de estos cuatro elementos (causas) que componen el ente político, así como en la correcta distribución y límites de los distintos oficios sociales que al interior de cada estamento político realizan los hombres en vistas a la satisfacción del Bien Común, esto es, la subsistencia (autarquía) social.

2) La atenta lectura de sus textos nos lleva a pensar que nuestro autor entiende la causalidad en términos prácticos más que metafísicos. Se trata de un recurso teórico (lógico) utilizado por él que más que dar razón del ser de lo político explica intrínsecamente la forma como se estructura y como debiera funcionar la sociedad. En este sentido, la consideración utilitaria, concreta, de la causalidad final conduce a nuestro autor medieval a distinguir, y en última instancia a excluir, toda explicación sobrenatural, esto es, trascendente del Bien Común (fin último perfecto de la vida humana). En este contexto, toda explicación extrínseca, esto es, meta-física y/o teológica de la sociedad, carecen de importancia.

3) Mientras las formas en Aristóteles, por ser de naturaleza distinta de la materia no se confunden con ella, esto es, son permanentes e inalterables, aún cuando intrínsecamente se dan en la materia, en Marsilio se concretizan por acción del gobernante, asamblea, o legislador, al punto de depender de ellos. Por tanto, se reduce su universalidad objetiva, esto 
es, se particularizan e individualizan en cuanto surgen, en última instancia, de la voluntad del pueblo (causa material). Dicho en otros términos, mientras en la tradición greco-medieval las formas (configuración, modelo, leyes) se des-cubren, en Marsilio más bien se generan. Por tanto, en este contexto, la causa formal, eficiente, y material, se igualan perdiendo, por consiguiente, la radical diferencia ontológica que las caracteriza.

4) Si bien Marsilio no niega la ley natural ni la ley eterna, su postura conduce a afirmar la arbitrariedad de las leyes humanas. Al restar importancia a la ley natural y/o excluir toda referencia a la ley eterna (divina) por su esencial diversidad de fines, las leyes humanas no refieren ni se someten a un orden moral superior, sino que se convierten, en última instancia, en convenciones entre los hombres sobre lo que está bien y es adecuado al momento en que se generan ${ }^{7}$; responden básicamente a la voluntad del legislador (pueblo): "lo que place al legislador, esa es la ley". Excluida la ley natural, no queda otro recurso que acudir a la razón práctica para asegurar la convivencia entre los hombres. Dicha razón coincide en nuestro autor con la voluntad del legislador, siendo éste una persona o la parte de más valor, o como diríamos en nuestros días, una comunidad o agrupación social. En todo caso, se trata de establecer por vía de la voluntad qué se puede o no hacer. En consecuencia, el Estado, significado entonces por el legislador, es quien determina lo que es bueno y útil para la comunidad.

5) La explícita importancia y primacía que atribuye nuestro autor a la causa material (pueblo) en cuanto legislador y generador del poder de la causa eficiente (gobernante), al margen del reduccionismo metafísico que ello implica (materialismo), conduce a la relativización del Estado, esto es, a la perdida de la trascendentalidad de las formas, es decir, de su "ejemplaridad" encarnada ya sea en las mismas leyes o en la figura virtuosa (formal) del gobernante ${ }^{8}$.

7 "La ley humana es un precepto del conjunto de ciudadanos, o de su parte prevalente, que debe legislar de modo inmediato y por su propia deliberación acerca de los actos humanos voluntarios que cada uno debe realizar o guardar en esta vida para alcanzar el mejor fin o estado que conviene a todo hombre en este mundo" (de Padua, 2004: 88).

8 "De acuerdo con lo dicho nos queda demostrar la causa eficiente del gobierno, por la cual a alguno o a algunos se da la autoridad de gobernar que se ha establecido por la elección. Pues por esta autoridad se constituye en acto el gobernante, no por su ciencia de las leyes, prudencia o virtud moral, aunque sean éstas las cualidades del gobernante perfecto. Ocurre, en efecto, que muchos poseen estas cualidades y, sin embargo, careciendo de aquella autoridad, no son gobernante si no es en potencia cercana" (de Padua, 2009: 73).

VERITAS, No 35 (Septiembre 2016) 
6) La concepción política naturalista de Marsilio parte de un factum (civitas naturalis) y un ius que propone como programa o modelo ejemplar (forma) que organiza la vida de la ciudad (Estado). Concluye su análisis en una teoría del poder que asume la forma de un pacto social. En este contexto es la totalidad de la civitas quien legitima el principio de coercitividad, esto es, la capacidad de disponer y ordenar del Estado. Con ello el pacto social se legitima en la parte gobernante logrando así la unidad (indivisibilidad) y la inalienabilidad del poder: el soberano (pueblogobernante) debe ser uno, singular, es decir, no permite la existencia de otro elemento con el cual compartir el poder, de ahí su rechazo al poder civil del sacerdocio y el esfuerzo por subordinarlo al poder del Estado. Dicha cuestión se manifiesta, además, en el monopolio de la capacidad de legislar y de administrar la justicia como atribución exclusiva del Estado.

7) Profundizando lo enunciado hasta aquí, es posible afirmar que en nuestro autor se encuentran claramente tres visiones (supuestos) del Estado correspondientes a distintas tradiciones filosóficas que intenta superponer sin que se opongan, a saber:

a) El Estado es producto de la ordenación de la razón y su existencia se ordena al bien vivir de los hombres (causa final). Esta afirmación encuentra su fundamento en el modelo racional propuesto por la filosofía clásica griega: el Estado es explicado por fines racionales dispuestos a la consecución del bien vivir, fín último de la vida humana. En este contexto, la moral y las leyes se definen por la adecuación a dicho fin (Aristóteles).

b) A la autoridad política le compete en primer lugar la resolución de los conflictos (establecimiento de la paz) y por ello se define por la posesión del poder coercitivo. El Estado es visto aquí como el escenario (lugar común) y como el regulador de los conflictos sociales; sólo a él le compete legislar y administrar la justicia. Según esta visión el fin del Estado y de la autoridad política viene dado por el estructuramiento del poder coercitivo utilizado para controlar y manejar los conflictos sociales (Maquiavelo y Hobbes).

c) La única fuente de poder político legítimo es la voluntad o consentimiento de los ciudadanos (pueblo). Esta tercera variante intenta constituirse en el punto medio de las dos anteriores: es la voluntarista y republicana. En esta el Estado se define sólo por la voluntad del pueblo (Rousseau). Para Marsilio, la coerción encuentra aquí su fundamento en cuanto se trata de alcanzar la paz y la preservación del Estado como fruto del acuerdo (consenso) de los ciudadanos. Por tanto, la coerción tiene carácter de iure en cuanto se ajusta a la 
voluntad del pueblo. Dicho en otros términos, sólo es legítimo el gobierno que implique la sumisión voluntaria de los ciudadanos. En este sentido, el republicanismo del Paduano resulta aquí evidente en cuanto es indispensable para alcanzar el fin (bien vivir) de la sociedad política.

8) La teoría política Marsiliana oscila entre dos elementos radicalmente distintos que a su modo complican la legitimidad del Estado, tema que se deja entrever en su concepción de la civitas y en particular en el método de su ciencia política: el recurso a ratione con el recurso ab auctoritate, por una parte la naturaleza (razón) y, por otra, lo sobrenatural (fe), hecho que dualiza a su vez el status de su ciencia política. En efecto, en su calidad de ciencia demostrativa (racional) lo político supone naturalmente el uso de la razón y la libertad de elección del agente humano. Cuando la entiende a partir de la fe, la politicidad aparece con posterioridad a la situación de pecado (original) en el que se encuentra el hombre. Es en este contexto donde el hombre racionalmente debe descubrir los medios necesarios para el bien vivir y en donde se plantea el conflicto (crisis) entre razón y fe, entre Estado e Iglesia y que Marsilio intenta solucionar subordinando políticamente la Iglesia al Estado. Se trata en el fondo, tal como afirma Habermas en nuestros días a propósito de las formas de gobierno contemporáneas, de una justificación no religiosa de los principios normativos del Estado constitucional democrático (Habermas \& Ratzinger, 2008: 11).

9) Reflexionando sobre las consecuencias de la enorme ruptura establecida por Marsilio entre fe y razón, podemos ver en ella el origen principal de algunos errores posteriores más importantes que han afectado el pensamiento occidental. En efecto, el liberalismo por él sustentado (independencia y/o exclusión de un orden social metafísico trascendente) se constituirá siglos más tarde en el fundamento ideológico del racionalismo político, del idealismo filosófico, de la Ilustración y, en último término, de algunos de los principales postulados socio-políticos de la modernidad. Y lo es porque deja al pensamiento humano sin referentes, sometido únicamente a su propia parcialidad, esto es, a su subjetividad. Sin un referente superior metafísico, trascendente, queda únicamente la razón y la voluntad individual como único rector de la conducta personal y colectiva. Dado que la razón no tiene como fin último "verdades eternas" (Ley Eterna, por ejemplo), entonces se subjetiva, por lo que cada uno tendrá en último término "su" propia razón. Dicha cuestión -no vislumbrada ciertamente por Marsilio- conlleva implícitamente la pugna entre subjetivismos al no haber un referente común (universal) que los 
unifique y en virtud del cual se pueda determinar cuál de ellos establece las normas de convivencia social; en este contexto resulta evidente que el subjetivismo vencedor será siempre el más poderoso, no el que tenga mayor razón. Con ello -como se puede observar- su pensamiento contribuirá implícitamente al establecimiento del fundamento intelectual del futuro totalitarismo en todos sus aspectos, esto es, del poder omnímodo del Estado. Así nace la ideología, con su carácter totalitario, cuyo principal postulado es considerar "su verdad" como la única posible y a cualquier otro pensamiento como indefendible y, por ello, atacable.

10) Desde Marsilio en adelante queda abierta, por tanto, la posibilidad que la subjetividad más poderosa sea la que determine lo que es bueno y lo que no lo es, sea esa subjetividad la de un tirano o la de un parlamento, puesto que ni el tirano ni la ley de la mayoría admiten lo común y universal trascendente. En este contexto la ley -como decíamos- se convierte en pura convención, modificable según la conveniencia de quien la establece. Por tanto, asistimos también el inicio del relativismo. Consciente o no de dicho problema, el liberalismo marsiliano propone encauzar esa subjetividad mediante la ley de las mayorías considerando que, cuando un número suficiente de personas, especialmente si son las mejores del colectivo (valentior o principans pars como le llama nuestro autor) se ponen de acuerdo en algo, ese algo será necesariamente lo mejor para la sociedad. Por la experiencia podemos juzgar hasta qué punto eso es cierto, esto es, hasta qué punto un parlamento reúne a "los mejores", y hasta qué punto esos "mejores" son capaces de determinar lo mejor para la sociedad. Históricamente existe sobrada experiencia para juzgar sobre ello. La pregunta y su respectiva respuesta que Marsilio no vislumbra es si puede la organización social subsistir sin un referente superior.

11) Siguiendo a W. Ullmann (1985) digamos, para terminar este artículo, que el autor del Defensor de la Paz se mueve en parte dentro del esquema medieval tradicional al distinguir gnoseológicamente, mas no realmente, la ley (causa formal) del gobierno (causa eficiente). No obstante, rompe con la tradición medieval cuando define a esta última como una norma coercible hecha por el hombre. Por ello -como bien afirma Ullmann- "es indudable que la originalidad de Marsilio no radica en sus razonamientos acerca de las tesis populistas, sino en negar, desde su punto de vista populista, legitimidad a cualquier tipo de gobierno que no se sometiera a las leyes elaboradas por los hombres" (Ullmann, 1985: 197). Se trata de un pensador de transición: por un lado anticipador del espíritu laico moderno, por otro un autor medieval que -a su juicio- ve en el 
Papa Juan XXII y los sacerdotes de su tiempo la causa de los problemas sociales que le toca vivir. Su gran aporte consiste en descubrir y proponer el espacio público como ámbito de emancipación política, tesis que encuentra en la autoconfiguración y legislación del Estado la instancia de máximo desarrollo y plenitud social del hombre.

\section{REFERENCIAS}

-Chapsal, M. (2013). Claves para comprender la separación razón-fe en el siglo XIII y sus implicancias filosóficas posteriores. Revista de Filosofía U. Católica de la Santísima Concepción, 12 (2), 47.

-de Padua, M. (2004). Sobre el Poder del Imperio y del Papa. El Defensor menor. La transferencia del imperio. Madrid: Editorial Biblioteca Nueva.

-de Padua, M. (2009). El Defensor de la Paz: Madrid: Editorial Tecnos.

-de Salisbury, J. (1984). Policraticus. Madrid: Editorial Nacional.

-Gilson, E. (1972). La Filosofía en la Edad Media. Madrid: Editorial Gredos.

-Godoy, O. (2003). Antología del Defensor de la Paz, de Marsilio de Padua. Estudios Públicos (90), 335-445.

-Habermas, J. \& Ratzinger, J. (2008). Entre razón y religión. Dialéctica de la seculariración. México: Fondo de Cultura Económica.

-Ullmann, W. (1985). Principios de Gobierno y Politica en la Edad Media. Madrid: Alianza Editorial.

Sumario: Introducción; 1. Origen de la Emancipación; 2. Hacia una disolución de la Iglesia; 3. Hacia una concepción laicista del Estado; A modo de conclusión; Referencias. 